\title{
Conflictos laborales en el sector salud del Perú
}

\author{
Labour disputes in the health sector in Peru
}

\author{
Flormarina Guardia Aguirre ${ }^{1}$, Javier Alva Gambini ${ }^{2}$, José Ramos-Castillo ${ }^{3,4}$ \\ 'Socióloga, Consultora en Politicas de Salud y Educación, Docente Universitaria. \\ ${ }^{2}$ Médico, Consultor de Politicas de Salud y Especialista en Recursos Humanos en Salud. \\ ${ }^{3}$ Médico, Policlínico Fiori, Red Asistencial Sabogal, EsSalud, Perú. \\ ${ }^{4}$ Facultad de Medicina, Universidad Nacional Mayor de San Marcos, Perú.
}

\section{An Fac Med. 2015;76:63-5 / doi:10.15381/anales.v76i1.10973}

\section{SEÑOR EDITOR,}

El crecimiento económico y la distribución desigual de sus beneficios han incrementado las tensiones sociales a nivel mundial. Ello se traduce en un crecimiento considerable de conflictos laborales entre empleadores y trabajadores en muchos países; situación que demanda un sistema de solución de conflictos laborales mediante arbitraje o conciliación, que actualmente carece de recursos y personal necesario. Según la OIT, los conflictos laborales constituyen enfrentamientos de posiciones que surgen entre grupos de personas en relación a las cuales existe una discrepancia entre trabajadores y empleadores, acerca de las cuales los trabajadores o empleadores expresan una reivindicación o queja; dichos conflictos pueden conducir el desarrollo de huelgas, interrupciones del trabajo, u otros tipos de medidas de reivindicación. Los salarios y la seguridad del empleo siguen siendo las causas principales de conflicto laboral. Por ello, la existencia de organizaciones de trabajadores y de empleadores así como el efectivo reconocimiento del derecho de negociación colectiva constituyen herramientas esenciales para mejorar las relaciones laborales y contribuir a la paz laboral necesaria para asegurar el desarrollo económico y social estable ${ }^{(1)}$.

Los conflictos laborales son inherentes a toda organización, dado que las interacciones humanas se caracterizan por el desacuerdo y conflicto; así, la presencia de ellos es considerada inherente a la dinámica de toda organización y en ocasiones necesarios, a pesar que sus consecuencias pueden ser positivas o negativas. Los conflictos laborales son conflictos sociales enmarcados en el área de trabajo, donde el empleado reclama al empleador la mejora de sus condiciones laborales ${ }^{(2)}$.

En la década pasada en nuestro país, en el contexto político de retorno a la institucionalidad democrática, se generaron demandas sociales contra los derechos laborales recortados, precarización del empleo, y disminución de salarios. En el sector salud se restablecieron los procesos de nombramiento laboral, asignaciones extraordinarias por trabajo asistencial y promoción de leyes que garantizaban el ejercicio profesional. Sin embargo, estos procesos fueron paulatinos y con dificultades para la negociación, lo que originó una serie de conflictos laborales ${ }^{(3-5)}$.
Es así que comunicamos, mediante la presente carta, los resultados de la investigación "El Conflicto Laboral en Salud 2001 - 2010", realizada por Flormarina Guardia y Javier Alva en el año 2010 y financiada por el Observatorio Nacional de Recursos Humanos en Salud, de la Dirección General de Gestión del Desarrollo de Recursos Humanos del Ministerio de Salud.

En dicho estudio se utilizaron fuentes de información secundarias, mediante búsqueda documental en la Defensoría del Pueblo y medios de difusión pública, como la Revista del Observatorio Social de América Latina del Consejo Latinoamericano de Ciencias Sociales y la Revista Construyendo Democracia del Observatorio Social del Centro de Estudios y Promoción del Desarrollo; así como en diarios de circulación nacional. Se consideraron los conflictos laborales expresados en huelgas indefinidas, paros y acciones de protesta, realizados por médicos, enfermeras, obstetrices, técnicos de enfermería y personal administrativo, tanto del MINSA y EsSalud, en base a sus demandas de remuneraciones, nombramientos, administrativos (equipamiento e infraestructura) y de gestión. 
En el periodo de estudio existieron 185 conflictos laborales en el sector salud, los cuales se manifestaron mediante 31 huelgas indefinidas (17\%), 73 paros $(40 \%)$, y 81 (43\%) diversas formas de acciones de protesta: plantones, marchas de sacrificio, toma de locales.

Estos conflictos laborales fueron de alcance nacional en un $29 \%$ y de carácter regional en $71 \%$. El sector mayormente afectado fue el Ministerio de Salud, tanto en Lima como de manera descentralizada a través de los Gobiernos Regionales. Las regiones donde se halló mayor cantidad de conflictos (51\%) fueron: Ancash, Ayacucho, Lima y Piura. En seis regiones no se detectaron conflictos laborales: Apurímac, Amazonas, Huancavelica, Lima Provincias, Madre de Dios y Ucayali. La demanda de los trabajadores de salud del ámbito hospitalario fue mayoritariamente vinculada a temas de gestión, en 41\%; la mayor demanda de los trabajadores del MINSA fue por nombramientos, en 67\%; la mayor demanda de los trabajadores de EsSalud fue por incremento de salarios, en 33\%.

En cuanto a grupos ocupacionales, tanto los médicos del MINSA y EsSalud así como las enfermeras, técnicos de enfermería, obstetrices y personal administrativo demandaron mayoritariamente un incremento en sus remuneraciones. Destacan por su duración en el periodo 2001-2010, la Huelga Médica de la Federación Médica del Perú del año 2008 que duró 43 días, la Huelga de Salud de la Región Loreto del año 2008 (que agrupó a todos los trabajadores de salud ) y duró 48 y 60 días, ya que ocurrió en dos momentos diferentes de ese año; la Huelga del Hospital La Caleta en la Región Ancash del año 2009 que duró 130 días y la Huelga de Salud de la Región Ayacucho del año 2010 que duró 104 días.

Si bien la respuesta ante los conflictos laborales va desde la aceptación hasta la represión, en todos los conflictos laborales mencionados en nuestro estudio, la respuesta inicial por parte de los empleadores tanto a nivel central como regional consistió en no iniciar el diálogo, junto al desconocimiento de las organizaciones huelguistas y la declaración de ilegalidad de sus medidas. Ello a pesar que los conflictos laborales son eventos previsibles y regulados mediante documentos internacionales o nacionales, como la Constitución Política del Perú, que facultan y reconocen estas acciones ${ }^{(4,6,7)}$.

En todos los conflictos de alcance mayor se abrió al cabo de un lapso un proceso de negociación, pero por fuera del ámbito de responsabilidad directa de la autoridad involucrada, sean estos Directores de Gobiernos Regionales o autoridades el Ministerio de Salud. Esto, aunado a las propias circunstancias del manejo del conflicto, terminaron en los casos estudiados, con la deslegitimación de la autoridad y generalmente con su salida, generando situaciones que repercutieron en la gobernabilidad sectorial en las regiones, tal como ocurrió en las demandas del sector salud de algunos países que tuvieron demandas similares a las halladas en nuestro estudio; es decir, el incremento de remuneraciones ${ }^{(8)}$.

En nuestro país, siendo la demanda más frecuente y previsible el incremento de remuneraciones, y considerando que el acto médico es invaluable, aún no se ha estandarizado los honorarios acorde a la complejidad del acto mismo ${ }^{(9)}$. Es preciso mencionar que los médicos peruanos perciben remuneraciones menores que en otros países de la región, lo que ha llevado a la implementación de una nueva escala salarial del MINSA y EsSalud en el presente año, no exenta también de conflicto laboral. En países como República Dominicana y Bolivia, el incremento de remuneraciones también fue la demanda más frecuente y la que mayor conflicto laboral suscitó en la década pasada ${ }^{(10)}$. Además, existen diferencias en el salario del personal de salud del Perú, de acuerdo a la institución y tipo de contrato al que pertenece el trabajador ${ }^{(11)}$.

Otro aspecto a considerar es la demanda por nombramiento en lugar de contratos, lo que evidencia el reclamo de estabilidad laboral definitiva contemplado en las leyes laborales peruanas, pero de cumplimiento irregular por parte de los empleadores, tal como ocurre en otros países ${ }^{(10,12)}$.

La negociación colectiva es un medio de alcanzar soluciones favorables y productivas en las relaciones entre trabajadores y empleadores, que generalmente pueden tener diversos niveles de conflictividad. La negociación está consagrada desde 1949 a nivel internacional, junto a la sindicalización, como uno de los derechos laborales fundamentales (Convenio $N^{\circ} 98$ Sobre el Derecho de Sindicación y de Negociación Colectiva, 1949). Proporciona medios para generar confianza entre las partes mediante la negociación, la articulación y la satisfacción de los intereses diversos de las partes negociadoras. La negociación colectiva desempeña esta función mediante la promoción de una participación pacífica, integradora y democrática de las organizaciones representativas de trabajadores y de empleadores ${ }^{(1)}$; asimismo, no anula ni limita los mecanismos y medios propios de la demanda reivindicativa gremial.

La conciliación voluntaria y el arbitraje pueden desempeñar un importante papel en la prevención y resolución de conflictos. Muchos sistemas jurídicos están, por tanto, alentando el uso de los procesos de conciliación y mediación como una manera eficaz de gestionar el conflicto laboral y aliviar la presión en los tribunales. Según la OIT, países como Chile o México llegan a tasas de $10 \%$ de sus trabajadores públicos en quienes se realiza la negociación colectiva $^{(13)}$.

En todos los casos de conflicto laboral de nuestro estudio tuvieron una participación activa los gremios y sindicatos de los trabajadores ${ }^{(10)}$. Asimismo, se encontró una limitada participación de los colegios profesionales.

En nuestro estudio, se evidencia la nula predisposición al diálogo y negociación colectiva, a pesar de ser una recomendación de la OIT. Por tanto, den- 
tro de las recomendaciones formuladas, se consideró la creación de una Unidad de Prevención y Solución de Conflictos Laborales, como parte de la estructura dela Dirección General de Gestión del Desarrollo de Recursos Humanos, que se encargue del registro y seguimiento así como la prevención de los conflictos laborales, tal como ocurre en otras realidades ${ }^{(14)}$. Dicha unidad de prevención y solución de conflictos laborales también fue recomendada por la PCM y se señaló que en su conformación debería tener asesoramiento de otras instituciones que ya disponen de unidades similares, como por ejemplo la Defensoría del Pueblo, Presidencia del Consejo de Ministros y el Ministerio de Trabajo ${ }^{(15)}$.

Dentro de las limitaciones de nuestro estudio se encuentra su carácter recopilatorio basado en fuentes secundarias, las mismas que pueden no abarcar la totalidad de conflictos laborales que se presentaron en determinado periodo. Por otro lado, nuestras fuentes de información podrían estar parcializadas u obviar algún aspecto. Los medios de difusión pública, por lo general, tampoco publican la modalidad de resolución de dichos conflictos, por lo que se podría añadir la posibilidad de otro sesgo a la información. Sin embargo, presentamos estos datos como una primera aproximación a nuestra realidad respecto a los conflictos laborales en el campo de la salud a modo de incentivo para la determinación de estudios cuantitativos y cualitativos sobre el tema. Este es un estudio pionero en el país en relación a los conflictos laborales en salud en el país y prácticamente uno de los pocos realizados en relación a esta temática, con excepción de un estudio cualitativo con un tema similar realizado en el 2011 en dos hospitales de Lima ${ }^{(16)}$ y otros estudios relacionados, como el estudio sobre salarios y remuneraciones ${ }^{(17)}$ y el estudio sobre la precarización del empleo en salud ${ }^{(18)}$; coincidentemente, se trata de estudios impulsados por el Observatorio Nacional de Recursos Humanos en Salud de la Dirección General de Gestión del Desarrollo de Recursos Humanos del MINSA.

La actual propuesta gubernamental de Reforma de Salud señala que el personal de salud es fundamental para el logro de los objetivos planteados; por lo tanto, estos deberían ser incluidos como parte de la Reforma y debe garantizarse su participación en los diferentes espacios de toma de decisiones y así contribuir a disminuir la conflictividad laboral.

Finalmente, debemos remarcar que el clima organizacional constituye un pilar para el adecuado funcionamiento de un sistema de salud ${ }^{(19)}$, y que la calidad de la vida laboral debe ser una aspiración y realidad, compartida por empleadores y empleados.

\section{REFERENCIAS BIBLIOGRÁFICAS}

1. Organización Internacional del Trabajo. La libertad de asociación y la libertad sindical en la práctica: lecciones extraidas. Conferencia Internacional del Trabajo $97^{\circ}$ reunión. $1^{\circ}$ ed. Ginebra: OIT, 2008:5-16.

2. Benitez M, Medina F, Munduate L. Estudio del conflicto en los equipos de trabajo. Una visión de las contribuciones científicas realizadas en España. Papeles del Psicólogo. 2011;32(1):69-81.

3. Arroyo J. Situación y desafíos en el campo de los recursos humanos en salud en el área andina, en los albores de los 2000. An Fac med. 2002;63(3):212-22.

4. Iturrizaga Urbina G. Diagnóstico y gestión de conflictos laborales en el sector salud. [Ponencia] Seminario 4. Dirección General de Gestión del Desarrollo de Recursos Humanos, Dirección de Gestión del Trabajo. Lima-Perú, 2010.

5. Lip C, Vargas A, Zevallos W, Longa J, Hurtado J. Situación del profesional médico cirujano a ocho años de iniciada la reforma de la salud y la seguridad social. An Fac med. 2000;61(2):99-124.

6. Defensoria del Pueblo del Perú. Ante todo, el diálogo. Defensoria del Pueblo y conflictos sociales y políticos. Lima, Perú: Defensoria del Pueblo, 2005:12 pp.

7. Buitrago F, Gamero Samino MJ, Vergeles Blanca JM, Cano Lozano MJ. ¿Influyen las huelgas de médicos en el perfil de utilización de los servicios de urgencias hospitalarios? Rev Esp Salud Pública. 1997;71(1):35-40.
8. Scavino J. La conflictividad de alcance nacional en el sector salud en la región de las Américas en el año 2003. Informe Anual de Conflictividad Laboral en las Américas; 2004.

9. Morales Landeo E. La ética del honorario médico. Acta Med Peru. 2004;21(1):54-6.

10. Arroyo J. Los sistemas descentrados de recursos humanos en salud: el caso del Perú, 1990-2005. Ciencia \& Saúde Colectiva. 2006;11(4):1063-72.

11. Pardo K, Andia M, Rodríguez A, Pérez W, Moscoso B. Remuneraciones, beneficios e incentivos laborales percibidos por trabajadores del sector salud en el Perú: Análisis comparativo entre el Ministerio de Salud y la Seguridad Social, 2009. Rev Peru Med Exp Salud Publica. 2011;28(2):342-51.

12. Dal Poz MR. Cambios en la contratación de recursos humanos: el caso del Programa de Salud de la Familia en Brasil. Gac Sanit. 2002;16(1):82-8.

13. OIT (internet). http://www.ilo.org/public/spanish/ support/lib/resource/subject/labourstat.htm Estadisticas y bases de datos, acceso 10/8/14.

14. Brito Quintana PE. Impacto de las reformas del sector de la salud sobre los recursos humanos y la gestión laboral. Rev Panam Salud Publica. 2000;8(1/2):43-54.

15. PCM. Presidencia del Consejo de Ministros, Oficina Nacional de Diálogo y Sostenibilidad. Willaqniki, Panorama General de la Conflictividad Laboral en el Perú. $8^{\circ}$ Ed. Lima, 2013:11 pp.

16. Gushiken Miyagui A. Los conflictos laborales en el sector salud desde la visión de los actores. En: UPCH. Salud Pública en el Perú aproximaciones y nuevos horizontes. Facultad de Salud Pública y Administración Carlos Vidal Layseca. Lima, 2014:151-82.

17. Ministerio de Salud. Análisis de remuneraciones, honorarios, bonificaciones e incentivos en MINSA y ESSALUD 2009. MINSA, Dirección General de Gestión del Desarrollo de Recursos Humanos, Observatorio Nacional de Recursos Humanos en Salud. Lima, 2011.

18. Reátegui Sánchez R. Precarización del Empleo en los Trabajadores de Salud y Propuesta de Políticas y Estrategias de Implementación en el Campo Laboral en Salud. En: Desafíos del empleo en salud: Trabajo decente, políticas de salud y seguridad laboral. Ministerio de Salud. Dirección General de Gestión del Desarrollo de Recursos Humanos en Salud. Observatorio Nacional de Recursos Humanos en Salud. Lima, 2011:15-66.

19. Romero González RE. Comportamiento organizacional. Nuevos retos, Miguel Ángel Porrúa, México, 2008:11 pp.

\section{Conflictos de interés:}

Los autores declaran no tener conflictos de interés.

\section{Correspondencia:}

Javier Alva

Correo elecrónico: jag10pe@gmail.com 